\title{
АНАЛИЗ ДИНАМИКИ БАЛАНСА ЗЕМЕЛЬ В ЦЕЛЯХ УПРАВЛЕНИЯ УСТОЙЧИВЫМ ПРОСТРАНСТВЕННЫМ РАЗВИТИЕМ ЗЕМЕЛЬ СЕЛЬСКОХОЗЯЙСТВЕННОГО НАЗНАЧЕНИЯ В РОССИИ
}

\section{Александр Павлович Сизов}

Московский государственный университет геодезии и картографии, 105064, Россия, г. Москва, Гороховский пер., 4, доктор технических наук, зав. кафедрой кадастра и основ земельного права, тел. (906)716-27-10, e-mail: ap_sizov@mail.ru

\section{Татьяна Владимировна Илюшина}

Московский государственный университет геодезии и картографии, 105064, Россия, г. Москва, Гороховский пер., 4, доктор географических наук, профессор кафедры кадастра и основ земельного права, тел. (916)915-06-19, e-mail: tilyushina@yandex.ru

\section{Ольга Витальевна Миклашевская}

Московский государственный университет геодезии и картографии, 105064, Россия, г. Москва, Гороховский пер., 4, старший преподаватель кафедры кадастра и основ земельного права, тел. (926)210-45-74, e-mail: miklashevski2004@yandex.ru

\section{Сергей Александрович Атаманов}

Московский государственный университет геодезии и картографии, 105064, Россия, г. Москва, Гороховский пер., 4, кандидат технических наук, доцент кафедры кадастра и основ земельного права, тел. (916)354-21-31, e-mail: sergey@atamanov.info

\section{Закир Сергеевич Косаруков}

Московский государственный университет геодезии и картографии, 105064, Россия, г. Москва, Гороховский пер., 4, старший преподаватель кафедры кадастра и основ земельного права, тел. (916)309-69-84, e-mail: kosarukovzs@gmail.com

Анализ показателей динамики баланса земель является одним из возможных вариантов реализации научной парадигмы «минимум исходной информации - максимум обоснованных обобщений». Приоритетными следует считать «активные» показатели - доли различных видов угодий в составе отдельных категорий земель от суммарной площади данной категории земель. С 2011 по 2017 гг. доля земель сельскохозяйственного назначения от всего земельного фонда в РФ уменьшилась с 22,75\% до 22,39\%, что свидетельствует об экстенсивном пространственном развитии территорий.

В качестве интегрирующего оценочного показателя для пространственного развития территорий, предлагается использовать скорость изменения долей различных угодий от площади земель различных категорий, \%/год, для сопоставимых периодов. С 2011 по 2017 г.г. скорость прироста доли сельскохозяйственных угодий в РФ возрастала в составе земель сельскохозяйственного назначения весьма существенно $(0,19 \% /$ год).

Доля лесных земель существенно уменьшилась в составе земель сельскохозяйственного назначения (-0,18\%/год), именно они послужили «источником» новых сельскохозяйственных угодий. Стабилизация доли земель под дорогами и нарушенных земель напоминает о необходимости интенсификации рекультивации земель и инфраструктурного обеспечения. 
Ключевые слова: баланс земель, ЕГРН, землеустройство, кадастр, категория земель, мониторинг земель, пространственное развитие, средоформирующий потенциал, территориальное планирование, территория, угодье

\section{ANALYSIS OF THE DYNAMICS OF LAND BALANCE IN ORDER TO MANAGE THE SUSTAINABLE SPATIAL DEVELOPMENT OF AGRICULTURAL LANDS IN RUSSIA}

\section{Alexander P. Sizov}

Moscow State University of Geodesy and Cartography, 4, Gorokhovsky Lane, Moscow, 105064, Russia, D. Sc., Head of the Department of Cadastre and Foundations of Land Law, phone: (906)716-27-10, e-mail:ap_sizov@mail.ru

\section{Tatiana V. Ilyushina}

Moscow State University of Geodesy and Cartography, 4, Gorokhovsky Lane, Moscow, 105064, Russia, D. Sc., Professor of the Department of Cadastre and Foundations of Land Law, phone: (916)915-06-19, e-mail: tilyushina@yandex.ru

\section{Olga V. Miklashevskaya}

Moscow State University of Geodesy and Cartography, 4, Gorokhovsky Lane, Moscow, 105064, Russia, Senior Lecturer of the Department of Cadastre and Foundations of Land Law, phone: (926)210-45-74, e-mail: miklashevski2004@yandex.ru

\section{Sergey A. Atamanov}

Moscow State University of Geodesy and Cartography, 4, Gorokhovsky Lane, Moscow, 105064, Russia, Ph. D., Associate Professor of the Department of Cadastre and Foundations of Land Law, phone: (916)354-21-31, e-mail: sergey@atamanov.info

\section{Zakir S. Kosarukov}

Moscow State University of Geodesy and Cartography, 4, Gorokhovsky Lane, Moscow, 105064, Russia, Senior Lecturer of the Department of Cadastre and Foundations of Land Law, phone: (916)309-69-84, e-mail: kosarukovzs@gmail.com

Analysis of indicators of the dynamics of the balance of lands is one of the possible options for the implementation of the scientific paradigm "minimum initial information - maximum reasonable generalizations". Priority should be given to "active" indicators - the share of different types of land in the composition of certain land categories from the total area of this land category. From 2011 to 2017 the share of agricultural land in the total land fund in the Russian Federation decreased from $22.75 \%$ to $22.39 \%$, which indicates the extensive spatial development of territories.

As an integrating assessment indicator for the spatial development of territories, it is proposed to use the rate of change in the shares of different lands from the area of lands of different categories, \% / year, for comparable periods. From 2011 to 2017 the rate of increase in the share of agricultural land in the Russian Federation increased significantly in the composition of agricultural land $(0.19 \%$ / year).

The share of forest land has significantly decreased in the composition of agricultural land $(-0.18 \%$ / year $)$, they served as the "source" of new agricultural land. The stabilization of the share of land under roads and disturbed land reminds of the need to intensify land reclamation and infrastructure provision.

Keywords: land balance, USRN, land management, cadastre, land category, land monitoring, spatial development, environmental potential, territorial planning, territory, land 
Результаты пространственного развития территорий необходимо диагностировать с помощью исчисления величины их средоформирующего потенциала, функционально зависящего от баланса угодий земель на конкретной территории [1]. Исчисление этого критерия обусловливает актуальность работы. Было разработано научное обеспечение государственной политики пространственного развития сельскохозяйственных территорий [2]. Как известно, земли сельскохозяйственного назначения являются стратегически важной категорией земель, что в очередной раз подчёркнуто в Доктрине продовольственной безопасности Российской Федерации, утверждённой Указом Президента РФ от 21.01.2020 № 20.

Целью исследования было уточнение возможностей методов традиционного анализа системы статистической информации для характеристики результатов пространственного развития сельскохозяйственных территорий и совершенствование количественных методов детекции состояния и использования земель сельскохозяйственного назначения. Были применены методы информационно-логического анализа в предметной области землепользования и прямого счёта.

Реновации отечественной имущественно-земельной парадигмы 20142015 гг. привели к возрастанию интереса к проблемам устойчивого развития территорий на информационной основе территориального планирования, землеустройства и единого государственного реестра недвижимости $[3,4]$. В это же время вступают в силу федеральный закон от 28.06.2014 № 172-Ф3 «О стратегическом планировании в Российской Федерации» и постановление Правительства РФ от 20.08.2015 № 870 «О содержании, составе, порядке разработки и утверждения стратегии пространственного развития РФ, а также о порядке осуществления мониторинга и контроля её реализации». Для реализации Стратегии необходимы подготовка и реализация проектных решений по землеустройству, кадастрам и территориальному планированию.

В результате принципиально иной становится перспективная цель регулирования земельно-имущественных отношений. Начиная с 2016-2017 и, усиленно, с 2019-2020 годов, необходимо обеспечить комплексное устойчивое пространственное развитие государства как геополитической единицы современного мондиалистского ${ }^{1}$ мира на фундаментальной основе цифровой пространственной информации. Толчком к этому стали принципиальные изменения международной обстановки. Задача удержания огромных территорий при постоянном оттоке населения с периферии в центр страны невозможна без правильного научно-методического обеспечения пространственного развития.

Словосочетание «пространственное развитие» встречается в разных источниках достаточно часто [5, 6], однако это понятие всё ещё достаточно дискуссионно, понимаясь специалистами различных отраслей неодинаково.

1 Этот термин, введённый в российский научный оборот в 1990е годы профессором А.Г.Дугиным и затем слегка подзабытый, на наш взгляд, точнее отражает современные геополитические реалии, чем более общие и в целом синонимичные термины «глобальный», «глобалистский» или «глобализированный». 
Европейским советом в целях совершенствования системы государственного планирования принята Европейская хартия регионального/пространственного планирования - первый документ по пространственному развитию, определивший тематику дальнейших международных исследований и ставший базисом выработки «Основополагающих принципов устойчивого пространственного развития европейского континента». В хартии введено понятие «spatial planning» (пространственное планирование), позволившее формализовать ряд задач эффективного планирования и развития территорий на современном уровне информатизации и разработки инфраструктуры пространственных данных (ИПД) на национальном и межгосударственном уровнях [7]. В европейской концепции пространственного развития (ESDP) именно пространственное планирование придает географическое выражение совокупности экономической, социальной, культурной и экологической политике общества, современный пространственный подход позволяет формализовать и интегрировать разнородную информацию. Введенное понятие в разных странах реализуется в соответствии со спецификой национальной истории формирования информационных ресурсов и разработкой национальной ИПД.

Для России характерна ситуация государственного централизованного подхода к задачам планирования развития государства и регионов. В решении этих задач периодически менялись местами исполнители главных ролей - основные «Тяжеловесы» государственного устройства: землеустроители или градостроители, но одновременно развивались географические основы природопользования. В настоящее время главные роли поручены градостроителям, что, учитывая исторические особенности «страны городов» и объективный процесс урбанизации, вполне правомерно. Но это означает, что градостроительное регулирование должно основываться на принципах экологически ориентированного природопользования $[4,8]$.В нашей стране анализ существующих правовых и методических документов выявил основной существенный недостаток - отсутствие консолидированного и системного экологического подхода в постановке задач территориального планирования.

Остро стоящая сегодня задача устойчивого развития территорий при одновременном сохранении благоприятной для человека окружающей среды требуют не ослаблять внимания к природоохранной составляющей земельных отношений. Пространственное развитие территорий может быть как экстенсивным (например, размещение увеличивающегося количества жителей в городе можно осуществлять, увеличивая площадь земель застройки при неизменной этажности зданий), так и интенсивныл (например, размещение увеличивающегося количества жителей в городе можно осуществлять, увеличивая этажность зданий при неизменной или даже снижающейся площади земель застройки).

Сущность процесса развития территорий дифференцируется в зависимости от категорий земель. Для земель сельскохозяйственного назначения к основным 
мероприятиям по пространственному развитию территорий относятся землеустройство, мелиорация земель, рекультивация земель, создание транспортнодорожной сети.

«Физическим» результатом пространственного развития территорий является изменение баланса земель (по категориям или по угодьям). В общем случае должна увеличиваться абсолютная площадь земель застройки, промышленности, энергетики, транспорта, связи и иного специального назначения; площадь же земель сельскохозяйственного назначения и лесопокрытых, как правило, уменьшается.

В конкретных ситуациях возможны иные варианты, но в любом случае для определённого технологического уклада достигается оптимальный баланс земель, устойчивый для некоторого более или менее длительного периода. Скачкообразное изменение баланса земель связано со сменой очередного технологического уклада.

Показатели динамики баланса земель мы предлагаем разделить на две группы:

- «пассивные» показатели - изменения долей отдельных категорий земель и отдельных видов угодий от суммарной площади территории за определённый промежуток времени;

- «активные» показатели - изменения долей отдельных видов угодий в составе отдельной категории земель от суммарной площади данной категории земель за определённый промежуток времени (возможен, но менее информативен, расчёт доли земель отдельных категорий в составе отдельного вида угодий от суммарной площади данного вида угодий).

Анализ динамики отдельных «пассивных» показателей широко применяется в описательной части докладов о состоянии и использовании земель РФ и её субъектов, анализ динамики «активных» показателей используется существенно реже. Впрочем, комплексный анализ динамики показателей баланса земель в РФ за длительный период времени затруднён из-за нередких изменений методик учёта земель и их несовершенства.

Исходя из нашего неизменного научного кредо «минимум исходной информации (по возможности, простой и доступной) - максимум обоснованных обобщений (по возможности, убедительных и понятных)», мы попытались реализовать практическую цель исследования таким образом, чтобы на основе легко доступных открытых данных с минимальными затратами были бы получены воспроизводимые результаты, отражающие динамические процессы развития территории РФ. Ряд таких данных ежегодно публикуется в документах Росреестра. Нами осуществлён опыт анализа динамики «активных» показателей на уровне РФ в целом за период 2011-2017 г.г. Была аккумулирована и обработана репрезентативная информация о балансе земель в формате распределения угодий по землям сельскохозяйственного назначения [9], наиболее динамично изменяющимся в РФ (табл. 1). 
Динамика распределения площадей различных угодий по землям сельскохозяйственного назначения (тыс. га)

\begin{tabular}{|c|c|c|l|c|c|c|}
\hline ГодІугодья & $\begin{array}{l}\text { Общая } \\
\text { площадь } \\
\text { категории }\end{array}$ & $\begin{array}{l}\text { Сельскохо- } \\
\text { зяйствен- } \\
\text { ные угодья }\end{array}$ & $\begin{array}{l}\text { Лесные } \\
\text { земли }\end{array}$ & $\begin{array}{l}\text { Земли за- } \\
\text { стройки }\end{array}$ & $\begin{array}{l}\text { Под доро } \\
\text { гами }\end{array}$ & $\begin{array}{l}\text { Нарушен } \\
\text { ные земли }\end{array}$ \\
\hline 2011 & 388972,0 & 196269,0 & 29132,5 & 1086,8 & 2299,0 & 205,6 \\
\hline 2015 & 383738,3 & 197749,1 & 24856,6 & 1099,8 & 2295,8 & 206,8 \\
\hline 2017 & 383227,7 & 197785,1 & 24513,9 & 1095,9 & 2294,2 & 206,0 \\
\hline
\end{tabular}

Изменения абсолютных площадей земель различных категорий и угодий (в единицах площади) неудобны для оценки динамики баланса, лучше воспользоваться относительными показателями (удельными, в расчёте на единицу площади, выраженными в долях от единицы или в процентах). Результаты пересчёта абсолютных показателей в относительные (удельные) приведены в табл. 2, где цветом выделены устойчивые тренды изменения долей угодий в составе земель различных категорий: голубым - уменьшение, коричневым - увеличение. Для наглядности тренды продублированы рисунком, однако, при в общем весьма небольшом количественном изменении долей, визуально тонкие изменения не столь заметны, как непосредственно по данным табл. 2.

Таблииа 2

Динамика долей различных угодий от площади земель сельскохозяйственного назначения (\%)

\begin{tabular}{|c|c|c|c|c|}
\hline Угодья & 2011 & 2015 & 2017 & Результат \\
\hline $\begin{array}{c}\text { Сельскохозяйствен } \\
\text { ные }\end{array}$ & 50,46 & 51,53 & 51,61 & прирост: $\uparrow$ \\
\hline Лесные земли & 7,49 & 6,48 & 6,40 & убывание: $\downarrow$ \\
\hline Земли застройки & 0,28 & 0,29 & 0,29 & $\sim$ const \\
\hline Под дорогами & 0,59 & 0,60 & 0,60 & $\sim$ const \\
\hline Нарушенные земли & 0,05 & 0,05 & 0,05 & $\sim$ const \\
\hline
\end{tabular}

Рациональное объяснение ситуации с не большими, но устойчивыми изменениями таково. Баланс земель как по категориям, так и по угодьям в столь большом по территории государстве, как РФ, весьма устойчив, и не может быть иным, так как значительная часть территории практически не используется в хозяйственной деятельности. Только длительное и планомерное пространственное развитие территории РФ может существенно изменить количественные данные баланса земель в целом по стране.

Следствием мизерности изменения долей угодий в составе земель различных категорий является наш постулат, что показатели динамики угодий в составе различных категорий земель должны использоваться в качестве количественных критериев развития отдельных субъектов РФ и отдельных территорий с особым статусом, в первую очередь тех, в которых происходит более 
интенсивная хозяйственная деятельность, связанная с пространственным развитием. Важным представляется исследование взаимосвязей между показателями динамики угодий и факторами, определяющими скорость такой динамики.

Были рассчитаны по формуле (1) скорости изменения долей различных угодий от площади земель сельскохозяйственного назначения $V_{\text {изм }}, \% /$ год, для периода с 2011 по 2017 г. (табл. 3).

$$
V_{\text {изм }}=\left(D^{t 2}-D^{t 1}\right) /\left(t^{2}-t^{1}\right)
$$

где $D^{t 2}$ - доля угодья от площади земель определённой категории на последующую дату, \%,

$D^{t 1}$ - доля угодья от площади земель определённой категории на предыдущую дату, \%,

$t^{2}$-последующая дата, год,

$t^{1}$ - предыдущая дата, год.

Положительные значения $V_{\text {изм }}$ соответствуют увеличению долей угодий в составе земель различных категорий, отрицательные - уменьшению.

Этот простой, но надёжный показатель предлагается использовать в качестве интегрирующего для оценки развития территорий, позволяющий ранжировать различные территории одного уровня при наличии сведений за одинаковый период времени.

Таблица 3

Скорости изменения долей различных угодий от площади земель сельскохозяйственного назначения (\%/год)

\begin{tabular}{|c|c|c|c|c|}
\hline $\begin{array}{l}\text { Сельскохозяйст } \\
\text { венные угодья }\end{array}$ & Лесные земли & $\begin{array}{l}\text { Земли за- } \\
\text { стройки }\end{array}$ & $\begin{array}{l}\text { Под доро- } \\
\text { гами }\end{array}$ & $\begin{array}{l}\text { Нарушен } \\
\text { ные земли }\end{array}$ \\
\hline $\mathbf{0 , 1 9}$ & $\mathbf{- 0 , 1 8}$ & const $^{2}$ & const & const \\
\hline
\end{tabular}

Обсуждение результатов. С 2011 по 2017 г.г. доля земель сельскохозяйственного назначения от всего земельного фонда в РФ уменьшилась с $22,75 \%$ до $22,39 \%$. Эта динамика соответствует современным российским представлениям о пространственном развитии территорий, но развитие это - экстенсивное.

Как выяснилось, наиболее информативным показателем динамики баланса земель сельскохозяйственного назначения является изменение доли сельскохозяйственных угодий, возрастающей весьма существенно со временем. Такое увеличение обусловлено как абсолютным приростом сельскохозяйственных угодий, так и снижением доли земель сельскохозяйственного назначения в земельном фонде РФ. Определённую роль сыграло и включение в границы РФ территории Крыма, богатого сельскохозяйственными угодьями. Эта тенденция возрастания

\footnotetext{
${ }^{2}$ Практически без изменений.
} 
доли сельскохозяйственных угодий для земель сельскохозяйственного назначения, безусловно, положительная.

Доля лесных земель существенно уменьшилась в составе земель сельскохозяйственного назначения. Таким образом, оказывается, что «источник» новых сельскохозяйственных угодий для земель сельскохозяйственного назначения это лесные земли (в современных условиях тенденция допустимая).

Остаётся постоянной доля угодий под дорогами, что свидетельствует об определённом дисбалансе в развитии земель сельскохозяйственного назначения, извечном отставании развития инфраструктуры. Не снижается доля нарушенных земель, что подтверждает известный факт недостаточности осуществления работ по рекультивации земель.

Выводы.

1) Анализ показателей динамики баланса земель является одним из возможных вариантов реализации научной парадигмы «минимум исходной информации (по возможности, простой и доступной) - максимум обоснованных обобщений (по возможности, убедительных и понятных)». Приоритетными следует считать «активные» показатели -доли различных видов угодий в составе отдельных категорий земель от суммарной площади данной категории земель.

2) В качестве интегрирующего оценочного показателя для пространственного развития территорий, позволяющего ранжировать различные территории одного уровня при наличии сведений за одинаковый период времени, предлагается использовать скорость изменения долей различных угодий от площади земель различных категорий, \%/год, для сопоставимых периодов.

3) С 2011 по 2017 г.г. доля земель сельскохозяйственного назначения от всего земельного фонда в РФ уменьшилась с $22,75 \%$ до $22,39 \%$, что соответствует современным российским представлениям о пространственном развитии территорий, но развитие это - экстенсивное.

4) С 2011 по 2017 г.г. доля сельскохозяйственных угодий в РФ возрастала в составе земель сельскохозяйственного назначения весьма существенно (скорость изменений составила $0,19 \% /$ год). Эта тенденция, безусловно, положительная.

5) Доля лесных земель существенно уменьшилась в составе земель сельскохозяйственного назначения $(-0,18 \% /$ год), именно они послужили «источником» новых сельскохозяйственных угодий.

6) Не снижается доля нарушенных земель, что подтверждает известный факт недостаточности осуществления работ по их рекультивации.

Статья выполнена по государственному заданию 0708-2020-0001 Министерства образования России.

\section{БИБЛИОГРАФИЧЕСКИЙ СПИСОК}

1. Сизов А.П., Кресникова Н.И., Сладкопевцев С.А., Братков В.В. Исчисление средоформирующего потенциала особо охраняемых территорий в границах сверхкрупного города в процессе государственного мониторинга его земель // Естественные и технические науки. 2018. - № 11(125). - С. 210-217. 
2. Сизов А.П., Крестникова Н.И., Илюшина Т.В., Литвиненко М.В. Научное обеспечение государственной политики пространственного развития сельскохозяйственных территорий // Естественные и технические науки.-2018. -№ 12(126). - С. 169-176.

3. Липски, С.А. Правовое обеспечение земельного надзора (контроля) и мониторинга земель / С.А.Липски. - Саратов: Изд-во «Ай Пи Эр Медиа», 2018. - 140 с.

4. Абросимов, В.В. Избранные проблемы и перспективные вопросы землеустройства, кадастров и развития территорий - 2017: Коллективная монография /В.В.Абросимов, Е.И. Аврунёв, О.М. Антонова, С.А. Атаманов, И.А.Басова и др.; под ред. А.П.Сизова. - М.: Русайнс, 2018. - 262 c.

5. Стребкова, А.Н. Развитие застроенных территорий [Электронный ресурс] / А.Н.Стребкова // Молодой ученый. - 2018. - № 47. - С. 293-295. - Режим доступа: URL https://moluch.ru/archive/233/54190/ (дата обращения: 08.09.2020).

6. Мезенина, О.Б. Развитие территорий муниципальных образований: цель, проблемы, предложения / О.Б.Мезенина, Д.А.Шаповалов // Московский экономический журнал. - 2019. № 3. - C. 17-25.

7. The European regional/spatial planning charter (Torremolinos Charter) (20.05.1983). [Electronic resource]. - https://rm.coe.int/6th-european-conference-of-ministers-responsible-for-regionalplanning/168076dd93; $\quad$ http://vasilievaa.narod.ru/mu/csipfo/kpr/frames/guide/erchapregspatplann.htm. <Европейская хартия регионального / пространственного планирования: принята на VI Конференции министров пространственного планирования (СЕМАТ) в Торремолиносе, Испания 20.05.1983). [Электронный ресурс]>.

8. Сизов, А.П. Развитие базовых понятий управления природными ресурсами и недвижимостью в целях адаптации окружающей среды под нужды человека /А.П.Сизов // Модели и технологии природообустройства (региональный аспект). - 2017. - № 4. - С. 85-95.

9. Сведения о наличии и распределении земель в Российской Федерации на 01.01.2012; на 01.01.2016; на 01.01.2018[Электронный ресурс]. - Официальный сайт Росреестра. Режим доступа: $\quad$ https://www.rosreestr.ru/site/activity/sostoyanie-zemel-rossii/gosudarstvennyynatsionalnyy-doklad-o-sostoyanii-i-ispolzovanii-zemel-v-rossiyskoy-federatsii/ (дата обращения: 08.10.2020).

(C) А. П. Сизов, Т. В. Илюшина, О. В. Миклашевская, С. А. Атаманов, 3. С. Косаруков, 2021 